\title{
Production and irradiation of ionic liquid cluster ions
}

$\operatorname{AUTHOR}(\mathrm{S}):$

Takaoka, Gikan H.; Takeuchi, Mitsuaki; Ryuto, Hiromichi; Ueda, Ryo

\section{CITATION:}

Takaoka, Gikan H. ... [et al]. Production and irradiation of ionic liquid cluster ions. Nuclear Instruments and Methods in Physics Research Section B: Beam Interactions with

Materials and Atoms 2013, 307: 257-259

ISSUE DATE:

2013-07-15

URL:

http://hdl.handle.net/2433/179395

\section{RIGHT:}

(c) 2013 Elsevier B.V.; この論文は出版社版でありません。引用の際には 出版社版をご確認ご利用ください。; This is not the published version. Please cite only the published version. 


\title{
Production and Irradiation of Ionic Liquid Cluster Ions
}

\author{
Gikan H. Takaoka*, Mitsuaki Takeuchi, Hiromichi Ryuto and Ryo Ueda \\ Photonics and Electronics Science and Engineering Center, Kyoto University \\ Katsura, Nishikyo-ku, Kyoto 615-8510, Japan
}

\begin{abstract}
We have developed a field-emission-type of cluster ion source using ionic liquids such as 1-butyl-3-methylimidazolium hexafluorophosphate (BMIM-PF $F_{6}$. The current obtained was stable by placing a porous cap around the emitter. Time-of-flight (TOF) measurement showed that the peak mass number was approximately 5000 for positive and negative $\mathrm{BMIM}-\mathrm{PF}_{6}$ ion beams. This indicated that $\mathrm{BMIM}-\mathrm{PF}_{6}$ clusters with a size of a few tens of molecules were produced. With regard to the surface modification by BMIM- $\mathrm{PF}_{6}$ ion beams, positive and negative cluster ion beams were used to irradiate Si(100) and glass substrates. Scanning electron microscope (SEM) and atomic force microscope (AFM) observations showed that the surface roughness of substrates increased. Furthermore, X-ray photoelectron spectroscopy (XPS) measurement showed that the composition ratio of layers deposited by positive or negative cluster ion beams was similar to that of BMIM-PF 6 solvent.
\end{abstract}

Keywords: Ionic liquids, Cluster ion, Negative ion, Field emitter, Surface modification 


\section{Introduction}

Ion-assisted materials processing has generated interest in surface treatments such as deposition and etching [1-3], and has been responsible for advancements of functional and useful materials such as silicon and glass. Ion beam technology is one example of ion-assisted material processing that has recently attracted attention due to the controllability and variety of ion beams that can be used. For example, various kinds of ions such as positive and negative ions, monomer and cluster ions, are available, and they are applied to various scientific and technological fields. In these ions, polyatomic molecular ions exhibit unique features, one of which is that it can transfer energy and mass as well as fragment radicals toward solid surfaces. These radicals play an important role in chemical erosion and modification of material surfaces.

Ionic liquids, which are molten salts with negligible vapor pressures, are opticaltransparent, electric-conductive, and thermal-stable materials. Ionic liquids, which contain polyatomic molecules consisting of a cation and an anion [4], can be decorated either on the cation or anion by introducing functional organic groups or metal ions $[5,6]$. They exhibit many features which are advantageous for a number of applications such as synthetic chemistry, catalysis, photochemistry and electrochemistry [7-10]. We have focused on their unique chemical and physical properties as well as wide liquids ranges, and have developed an ionic liquid ion source in order to produce various kinds of ions such as positive and negative ions, monomer and cluster ions.

Furthermore, a cluster state of polyatomic molecules has several unique features, for example, the clusters enable a link between the atomic state and bulk state. The physical and chemical properties of clusters are different to those of the bulk state $[11,12]$. In addition, the impact of cluster ions on solid surfaces is characterized by several unique irradiation effects, which include a high energy density, high mass density, multiple collisions, and low energy irradiation effects [13-15]. For example, the 
high energy density irradiation effect enhances the surface temperature of the impact region, which enhances the chemical reactions occurring on the surface. As a result, a high sputtering rate and a low damage irradiation was carried out even at room temperature on the silicon surfaces by using polyatomic cluster ions such as methanol and ethanol cluster ions $[16,17]$. In addition to unique properties of ionic liquids, the surface modification of silicon and glass substrates by ionic liquid cluster ion beams attracts much interest, and it opens up a new field of application for these ion-assisted material processing techniques. In this article, beam characteristics of ionic liquid ion beams are investigated, and production of positive and negative cluster ions is described. Furthermore, irradiation of ionic liquid cluster ions on silicon and glass substrates is performed at room temperature, and surface modification of the substrates is investigated.

\section{Experimental}

A polyatomic ion source using ionic liquids was developed. Ionic liquid used was 1butyl-3-methylimidazolium hexafluorophosphate (BMIM-PF 6 ). A high-electric field method was employed for the ion-emission from a sharp tip made of carbon rod. The diameter of the rod was $0.3 \mathrm{~mm}$. As a tip designed, a needle with a radius of $80 \mu \mathrm{m}$ was employed. The ions were extracted from the tip by applying the voltage between the tip and the extraction electrode. The extraction voltage was adjusted to be between $0 \mathrm{kV}$ and $8 \mathrm{kV}$. The aperture made on the extraction electrode was $3 \mathrm{~mm}$ in diameter, and the distance between the tip and the extraction electrode was $3 \mathrm{~mm}$. In order to remove electrons from negative ion beams, the magnetic field of $160 \mathrm{mT}$ was applied near the extraction aperture. The positive or negative ions extracted were accelerated toward a substrate, which was placed on a sample holder. The acceleraton voltage was adjusted to be between $0 \mathrm{kV}$ and $10 \mathrm{kV}$. The substrates used were silicon $(\mathrm{Si})$ and glass substrates, and the substrate temperature was room temperature. The background 
pressure around the substrate was $1.3 \times 10^{-4} \mathrm{~Pa}$, which was attained using a diffusion pump.

The mass analysis of ionic liquid ion beams was performed by a time-of-flight (TOF) method. To make TOF measurement, the extracted ion beams entered a flight tube, and they were deflected by a negative voltage pulse. Due to the application of this voltage, the ions drifted towards a Faraday cup mounted at the end of the flight tube, which detected the ions. The pulse voltage was $2 \mathrm{kV}$. The duration time and the repetition rate of the pulse voltage were $10 \mu$ s and $100 \mathrm{~Hz}$, respectively. The drift distance was $1.70 \mathrm{~m}$. The mass number was calculated based on the drift time, which ranged from microseconds to milliseconds and varied depending on the mass of the ions.

\section{Results and Discussion}

\subsection{Beam characteristics}

For the high-electric field emission of ions, the emission area is extremely small like a tip point. Therefore, high-density ion current is available, even if the extraction ion current is small. Figure 1 shows the dependence of the ion current of ionic liquid $\left(\mathrm{BMIM}-\mathrm{PF}_{6}\right)$ on the extraction voltage. Both positive and negative ions start to be emitted at an extraction voltage of approximately $5.0 \mathrm{kV}$. The ion current increases with increasing extraction voltage, and it is approximately $100 \mathrm{nA}$ at an extraction voltage of $6.5 \mathrm{kV}$. It should be noted that ionic liquid is a molten salt consisting of a cation and an anion. Therefore, the positive ions obtained correspond to cations, and the negative ions correspond to extracted anions. Furthermore, if amount of cations or anions extracted is much larger than that of anions or cations remained, the extracted current becomes unstable, for example, in an electro spray method. In this work, the porous cap was placed around the tip, and the stable current could be obtained by adjusting the porosity of the cap.

With regard to the threshold voltage $V_{t h}$, it is given by [18] 


$$
V_{t h}=\sqrt{\frac{\gamma r_{t}}{\varepsilon_{0}}} \ln \frac{4 d}{r_{t}}
$$

where $\varepsilon_{0}$ is the permittivity of vacuum, $\gamma$ is the surface tension of the liquid, $r_{t}$ is the radius of the tip point, and $d$ is the distance between the tip and the extraction electrode. The surface tension of BMIM- $\mathrm{PF}_{6}$ is $0.049 \mathrm{~N} / \mathrm{m}$. Also, the radius $r_{t}$ is $80 \mu \mathrm{m}$, and the distance $d$ is $3 \mathrm{~mm}$. Therefore, the threshold voltage is estimated to be a few kilovolts, and it is close to the experimental result, i.e. $5.0 \mathrm{kV}$.

Figure 2 shows the TOF spectra for positive and negative ionic liquid ion beams. The extraction voltage was $8 \mathrm{kV}$. As shown in the figure, the peak mass number is approximately 5000 for positive and negative ions, although the mass resolution is not sufficient. The molecular weight of cation $\left(\mathrm{C}_{8} \mathrm{H}_{13} \mathrm{~N}_{2}\right)$ and anion $\left(\mathrm{PF}_{6}\right)$ is 139.22 and 144.96, respectively. By assuming that singly charged ions are extracted, ionic liquid cluster ions with a size of approximately 18 molecules are produced. Thus, positive and negative cluster ions of ionic liquid $\left(\mathrm{BMIM}-\mathrm{PF}_{6}\right)$ with a relatively low vapor pressure can be produced by the high-electric field emission method. This method is different from a nozzle beam method [17], which uses the adiabatic expansion phenomenon for production of liquid clusters at a high vapor pressure. Furthermore, it is considered that ionic liquid clusters might have the ionic bonding ability and that a cation or an anion is attached to ionic liquid neutral-clusters resulting in positive or negative cluster ions.

\subsection{Composition ratio}

The composition of ionic liquid layers deposited on $\mathrm{Si}(100)$ substrates was measured by an X-ray photoelectron spectroscopy (XPS). Figure 3 shows a XPS spectrum for BMIM-PF 6 layers deposited by positive cluster ion beams. The acceleration voltage was $10 \mathrm{kV}$, and the fluence was $1.0 \times 10^{15} \mathrm{ions} / \mathrm{cm}^{2}$. As shown in the figure, XPS peaks such 
as $\mathrm{F}, \mathrm{N}, \mathrm{C}$, and $\mathrm{P}$ peaks are observed. These peaks correspond to the constituent elements in a BMIM-PF 6 molecule. $\mathrm{N}$ and $\mathrm{C}$ atoms are included in a cation, and $\mathrm{F}$ and $\mathrm{P}$ atoms are included in an anion. The composition ratio of these atoms is similar to that of ionic liquid (BMIM- $\left.\mathrm{PF}_{6}\right)$ solvent. According to the TOF measurement, ionic liquid cluster ions were found to be produced. Therefore, the inclusion of these constituent elements indicates that a cation is attached to the neutral BMIM-PF 6 cluster resulting in the formation of positive cluster ions. It should be noted that the composition ratio of $\mathrm{F}, \mathrm{N}, \mathrm{C}$, and $\mathrm{P}$ atoms was also similar to that of ionic liquid solvent for the negative cluster ion irradiation.

\subsection{Surface modification}

In order to prepare more functional glasses, the surface modification of glass substrates was performed. The surface states of glass substrates irradiated by BMIM$\mathrm{PF}_{6}$ cluster ions were measured by using an atomic force microscope (AFM) and a scanning electron microscope (SEM). Figure 4 shows SEM and AFM images of glass substrates irradiated by positive cluster ions. The extraction voltage applied to the tip was $6 \mathrm{kV}$. As shown in the figure, the SEM images of glass substrates are observed clearly without charge-up of electron beams. This is achieved by the deposition of ionic liquids exhibiting electric conductivity. Furthermore, the glass surface becomes rough after deposition, and the surface roughness $\left(R_{a}\right)$ is $0.53 \mathrm{~nm}$. It is larger than that of the unirradiated glass, such as $0.4 \mathrm{~nm}$.

In addition, optical properties of layers deposited on $\mathrm{Si}(100)$ and glass substrates by positive and negative cluster ion beams were investigated. The layers were transparent, and the transmittance was larger than $95 \%$. The contact angle of water droplet on deposited layers was between 40 and 50 degrees, which was similar to the substrate surface dipped by using the ionic liquid. Thus, the surface modification of Si(100) and glass substrates was performed with ionic liquid (BMIM-PF $\left.{ }_{6}\right)$ cluster ion beams. 


\section{Conclusions}

We developed a field-emission-type of cluster ion source using ionic liquids such as BMIM-PF 6 . The positive and negative ion current increased with increasing extraction voltage, and it was approximately $100 \mathrm{nA}$ at an extraction voltage of $6.5 \mathrm{kV}$. Also, the peak mass number was approximately 5000 for positive and negative ions. This indicated that BMIM-PF6 clusters with a size of a few tens of molecules were produced. Furthermore, both positive and negative cluster ion beams were obtained by changing the polarity of the extraction voltage applied to the tip.

With regard to the surface modification by BMIM-PF6 ion beams, positive and negative cluster ion beams were deposited on $\mathrm{Si}(100)$ and glass substrates. XPS measurement showed that the composition ratio of deposited layers was similar to that of the ionic liquid solvent. Furthermore, the surface roughness increased with increasing extraction voltage, and it was approximately $0.53 \mathrm{~nm}$ at the extraction voltage of $6 \mathrm{kV}$. Also, the layers with a transmittance of approximately $95 \%$ could be deposited on the glass substrates. The contact angle of deposited layers by positive and negative cluster ion beams was between 40 and 50 degrees, which was similar to that of BMIM- $\mathrm{PF}_{6}$ solvent. 
References

[1] H. Bernas and R.E. de Lamaestre, "Ion-Beam-Based Nanofabrication", edited by D. Ila, J. Baglin, N. Kishimoto and P.K. Chu (Mater. Res. Soc. Proc. 1020, Warrendale, PA, 2007), p.101.

[2] L. Bardos and H. Barankova, Vacuum, 83 (2009) 522.

[3] G. Brauer, B. Szyszka, M. Vergohl and R. Bandorf, Vacuum, 83 (2010) 1354.

[4] P. Lozano and M. Martinez -Sanchez, J. Colloid Interface Sci. 280 (2004) 149.

[5] L.N. Puntus, K.J. Schenk and J.-C.G. Bunzli, Eur. J. Inorg. Chem. (2005) 4739.

[6] A. Getsis, S. Tang and A.-V. Mudring, Eur. J. Inorg. Chem. (2010) 2172.

[7] T. Welton, Chem. Rev. 99 (1999) 2071.

[8] H. Zhao, J.E. Holladay, H. Brown and Z.C. Zhang, Science, 316 (2007) 1597.

[9] N.V. Plechkova and K.R. Seddon, Chem. Soc. Rev. 37 (2008) 123.

[10] E. Kowsari and G. Faraghi, Mat. Res. Bull. 45 (2010) 939.

[11]Ph. Buffat and J-P. Borel: Size effect on the melting temperature of gold particles, Phys. Rev. A13 (1976) 2287.

[12] M.D. Morse, Chem. Rev. 86 (1986) 1049.

[13] R.S. Averback, M. Ghaly and H. Zhu, Radiat. Eff. Defects Solids, 130-131 (1994) 211.

[14] Z. Insepov, I. Yamada and M. Sosnowski, Mater. Chem. Phys. 54 (1998) 234.

[15] H. Yasumatsu and T. Kondow, Rep. Prog. Phys. 66 (2003) 1783.

[16] G.H. Takaoka, H. Noguchi and M. Kawashita, Nucl. Instrum. Methods, B242 (2006) 417.

[17] G.H. Takaoka, H. Ryuto and M. Takeuchi, J. Mater. Res. 27 (2012) 806.

[18] R. Gomer, Appl. Phys. 19 (1979) 365. 


\section{Figure Captions}

Figure 1: Dependence of the ion current of ionic liquid $\left(\mathrm{BMIM}-\mathrm{PF}_{6}\right)$ on the extraction voltage.

Figure 2: TOF spectra for positive and negative ionic liquid ion beams.

Figure 3: XPS spectrum for ionic liquid layers deposited on Si(100) substrate by positive cluster ion beams. The acceleration voltage was $10 \mathrm{kV}$, and the fluence was $1.0 \times 10^{15} \mathrm{ions} / \mathrm{cm}^{2}$.

Figure 4: (a) SEM and (b) AFM images of glass substrates irradiated by positive cluster ions. The extraction voltage applied to the tip was $6 \mathrm{kV}$. 


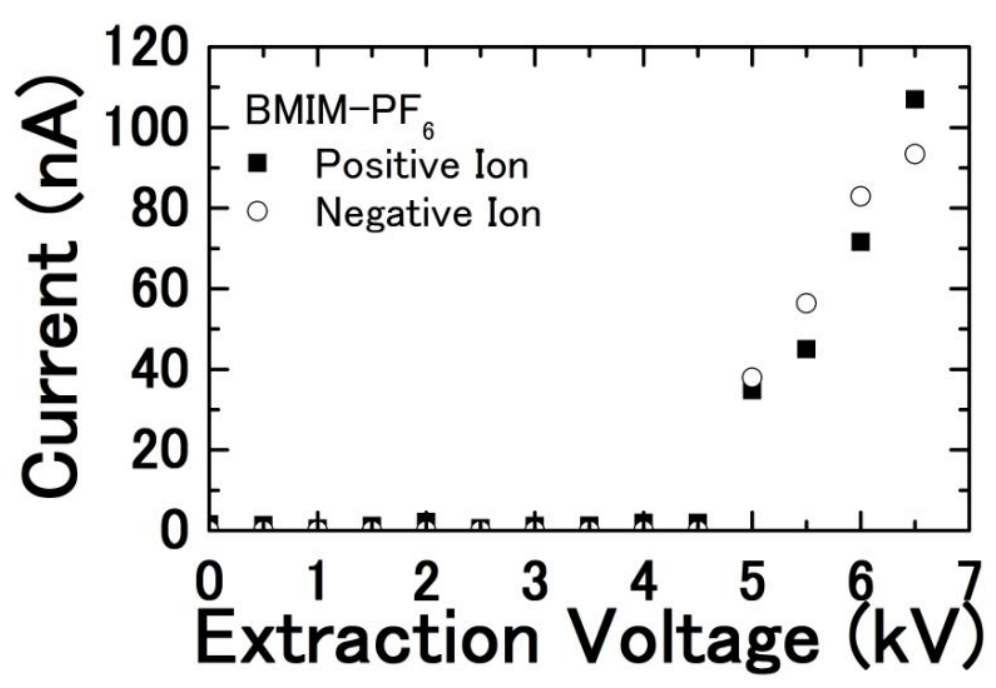

Figure 1: Takaoka et al. 


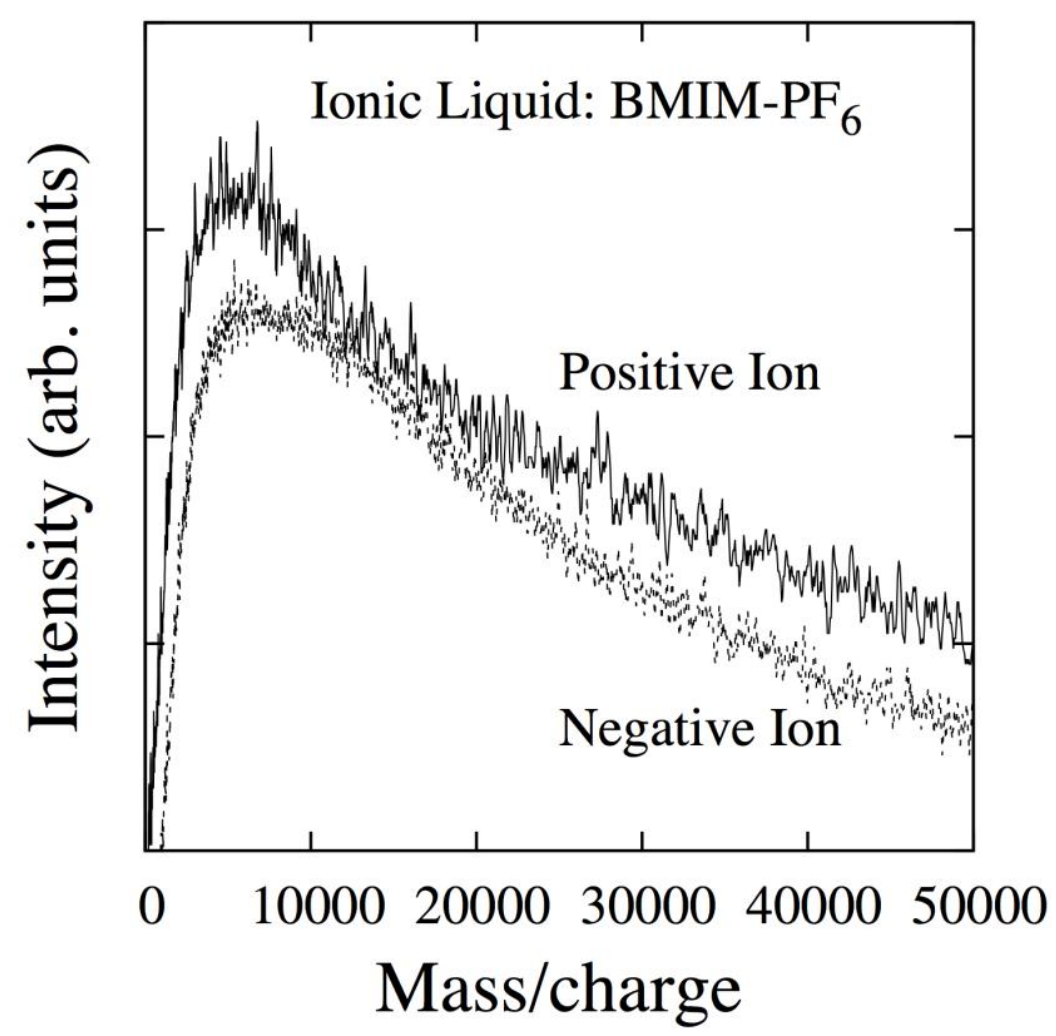

Figure 2: Takaoka et al. 


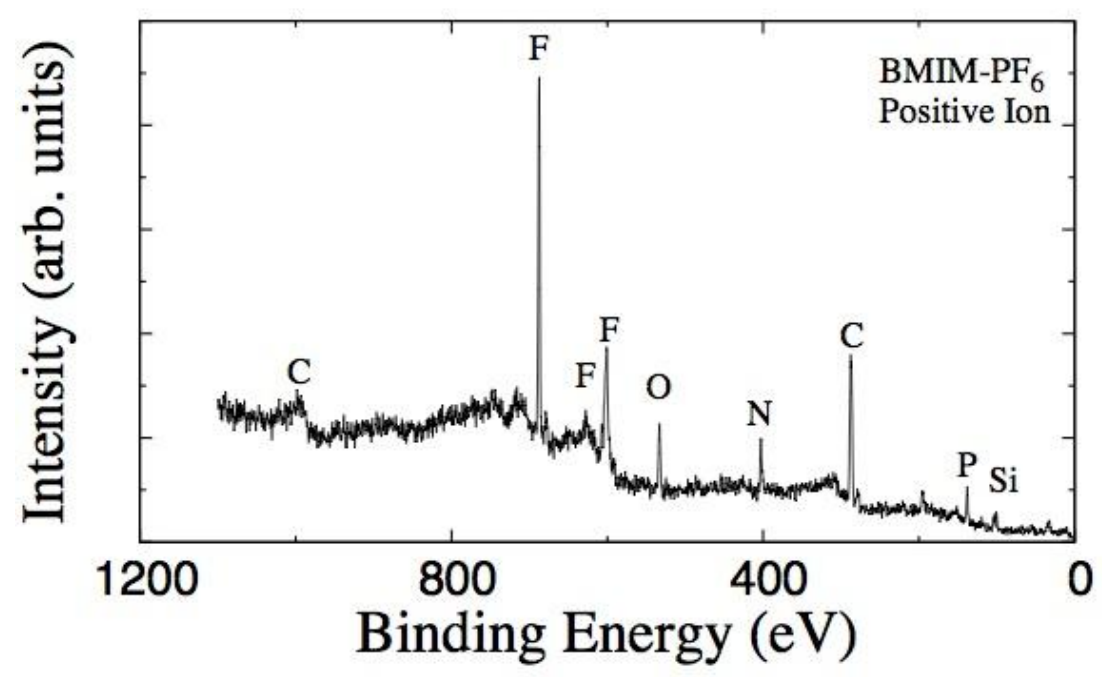

Figure 3: Takaoka et al. 

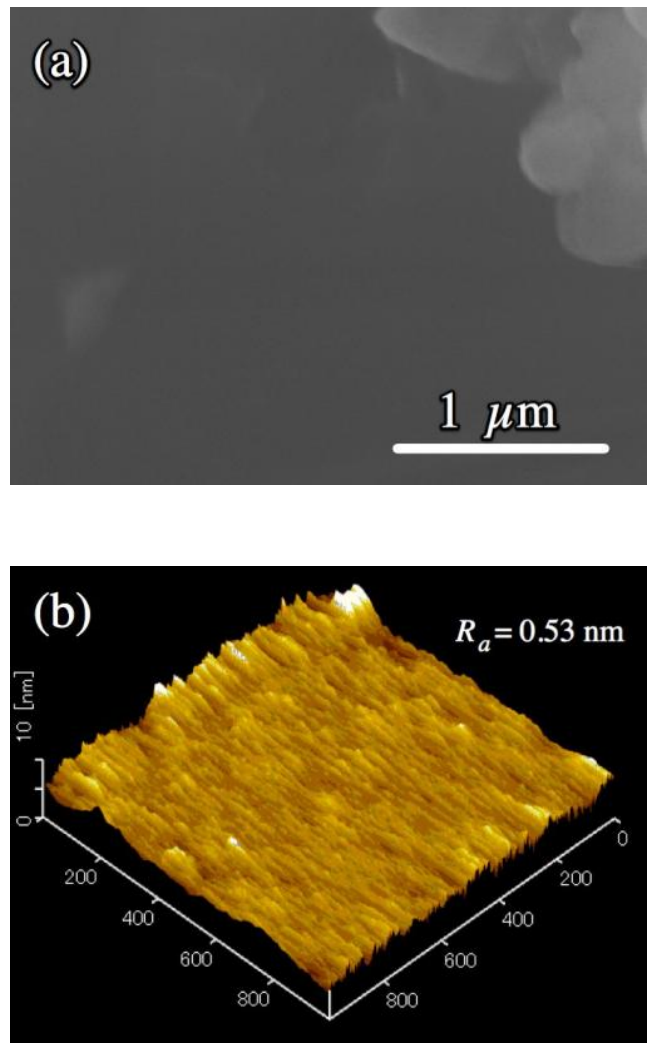

Figure 4: Takaoka et al. 